\title{
Supporting Information for \\ Functionalized Nanoparticles for the Dispersion of Gas \\ Hydrates in Slurry Flow
}

Xianwei Zhang, ${ }^{1 \dagger}$ Jingjing Gong, ${ }^{2 \dagger}$ Xingfu Yang, ${ }^{2}$ Britanny Slupe, ${ }^{2}$ Janice Jin, ${ }^{2}$

Ning $\mathrm{Wu},{ }^{2 *}$ and Amadeu K. Sum ${ }^{1 *}$

${ }^{1}$ Phases to Flow Laboratory, The Department of Chemical \& Biological Engineering, Colorado School of Mines, Golden, Colorado 80401, United States of America

${ }^{2}$ The Department of Chemical \& Biological Engineering, Colorado School of Mines, Golden, Colorado 80401, United States of America

*Corresponding authors E-mail: Ning Wu: ningwu@mines.edu; Amadeu K. Sum: asum@mines.edu.

†Author contributions: X. Zhang and J. Gong contributed equally to this work. 
Table S1. The average size of emulsions stabilized by different NPs.

\begin{tabular}{|c|c|c|c|c|c|c|}
\hline NPs & $\mathbf{0 . 2 5 X}$ & $\mathbf{0 . 5 X}$ & $\mathbf{1 X}$ & $\mathbf{2 X}$ & $\mathbf{4 X}$ & $\mathbf{8 X}$ \\
\hline $\begin{array}{c}\text { Emulsion } \\
\text { type }\end{array}$ & $\mathbf{O} / \mathbf{W}$ & $\mathbf{O} / \mathbf{W}$ & $\mathbf{W} / \mathbf{O}$ & $\mathbf{W} / \mathbf{O}$ & $\mathbf{W} / \mathbf{O}$ & $\mathbf{W} / \mathbf{O}$ \\
\hline $\begin{array}{c}\text { Emulsion } \\
\text { size }(\boldsymbol{\mu m})\end{array}$ & $\begin{array}{c}49.09 \pm \\
17.19\end{array}$ & $\begin{array}{c}291.27 \pm \\
138.86\end{array}$ & $\begin{array}{c}181.95 \pm \\
69.81\end{array}$ & $\begin{array}{c}192.95 \pm \\
58.95\end{array}$ & $\begin{array}{c}457.87 \pm \\
174.75\end{array}$ & Unstable \\
\hline
\end{tabular}

Table S2. List of supporting movie files.

\begin{tabular}{|c|c|c|c|c|}
\hline File name & NP & $\begin{array}{c}\text { T } \\
\left({ }^{\circ} \mathbf{C}\right)\end{array}$ & $\begin{array}{c}\text { Speed relative to the } \\
\text { normal time }\end{array}$ & Comments \\
\hline Movie_S1_1x_hyd & $1 \mathrm{X}$ & 0.5 & 4 times & Dispersed hydrate particles \\
\hline Movie_S2_2x_ice & $2 \mathrm{X}$ & -15 & 4 times & Agglomerated ice particles \\
\hline Movie_S3_2x_hyd & $2 \mathrm{X}$ & 0.5 & 4 times & Agglomerated hydrate particles \\
\hline
\end{tabular}



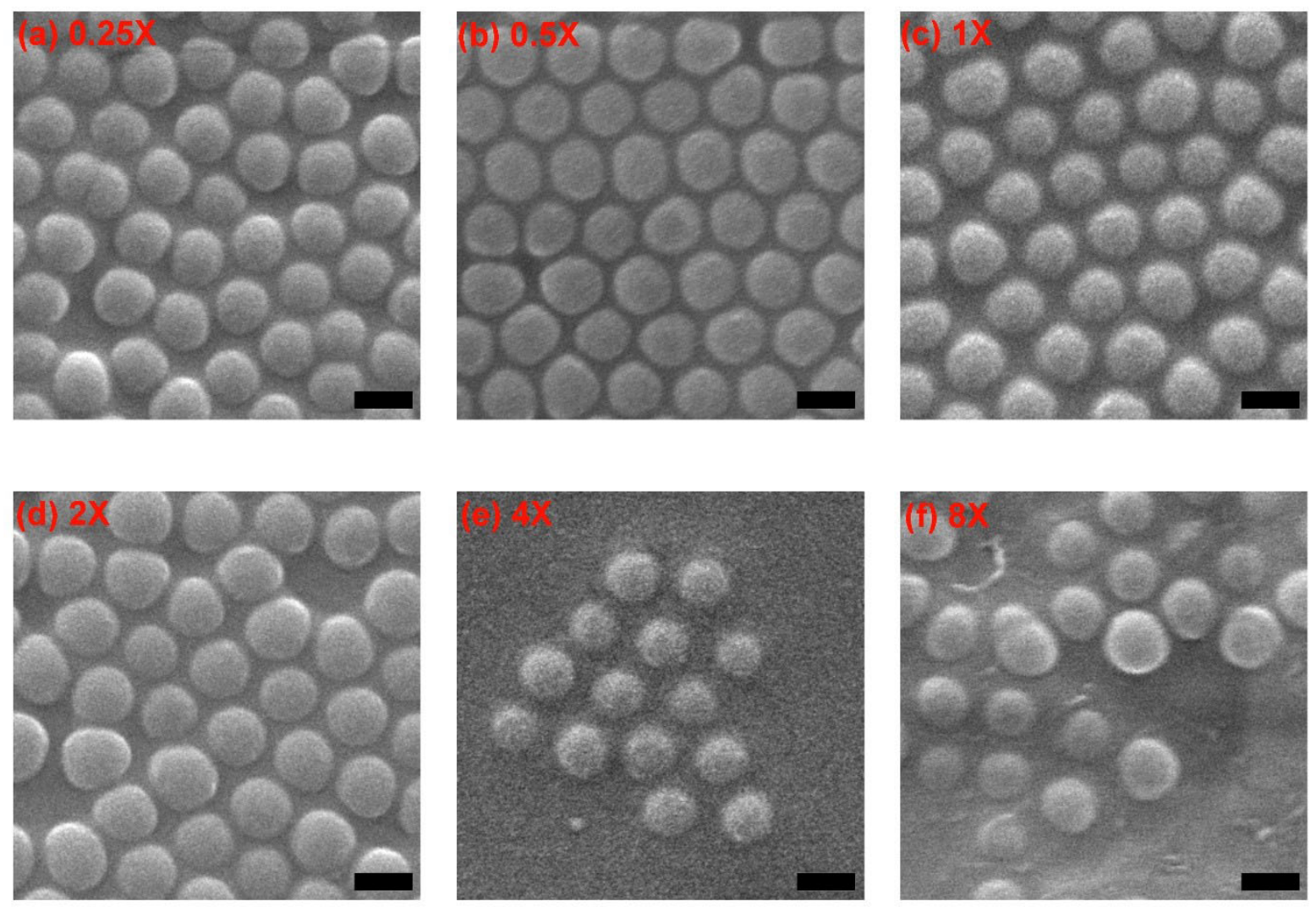

Figure S1. SEM images of modified silica NPs embedded in PDMS. Scale bars: $200 \mathrm{~nm}$. (a)-(f) shows the results of $0.25 \mathrm{X}, 0.5 \mathrm{X}, 1 \mathrm{X}, 2 \mathrm{X}, 4 \mathrm{X}$, and $8 \mathrm{X} \mathrm{NPs}$, respectively. 
(a)

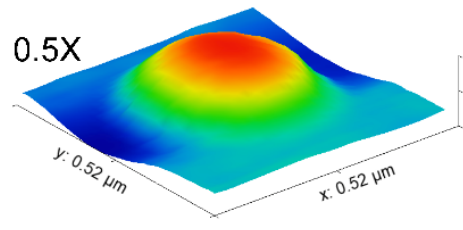

(d)

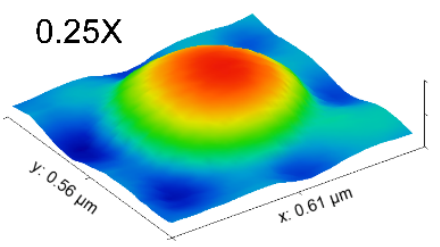

(b)

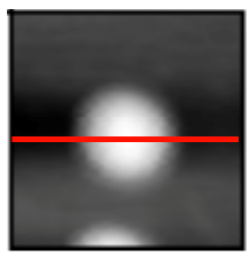

(e)

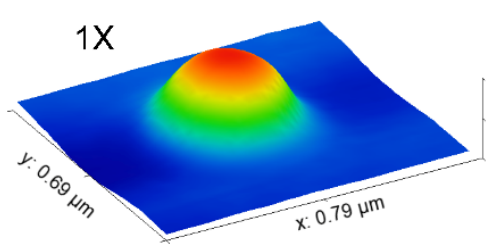

(c)

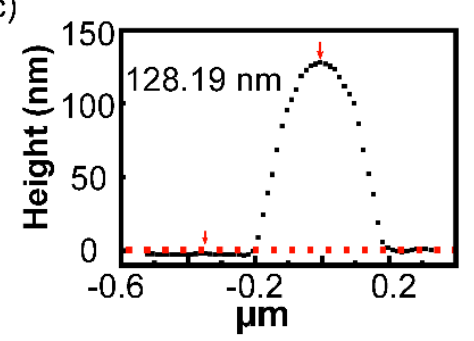

(f)

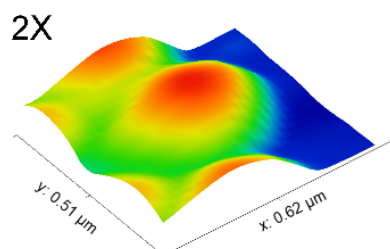

Figure S2. AFM height scan of modified silica NPs embedded in PDMS. (a) AFM image shows a $0.5 \mathrm{X}$ silica NP embedded in the PDMS. (b) a line across the center of the 0.5X silica NP. (c) corresponding height plot of the $0.5 \mathrm{X}$ silica NP embedded in the PDMS. (d) AFM image of a $0.25 \mathrm{X}$ silica NP embedded in the PDMS. (e) AFM image of a $1 \mathrm{X}$ silica NP embedded in the PDMS. (f) AFM image of a $2 \mathrm{X}$ silica NP embedded in the PDMS.
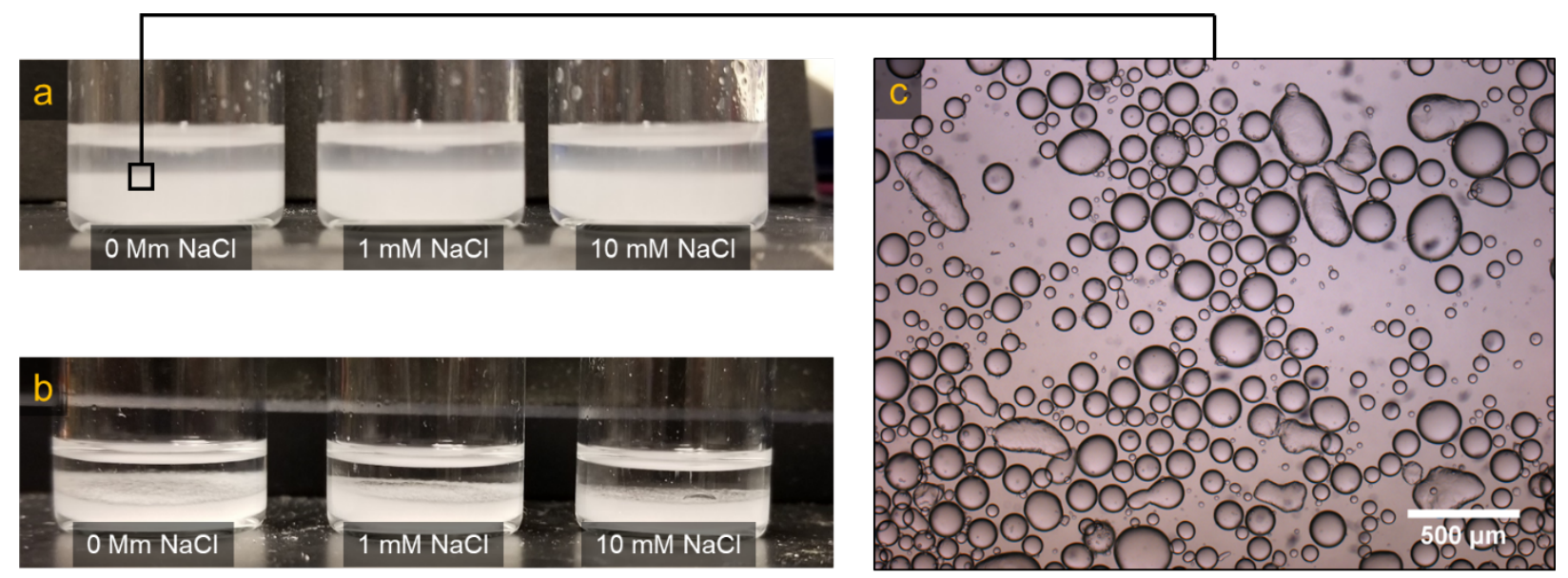

Figure S3. Images of the W/O emulsion stabilized by 1XS NPs. (a) Right after mixing. (b) After 4 weeks. (c) Optical microscope image of the Pickering emulsions right after mixing. 
(a) $21^{\circ} \mathrm{C}$

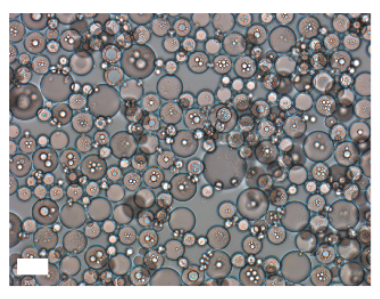

(b) $-15^{\circ} \mathrm{C}$

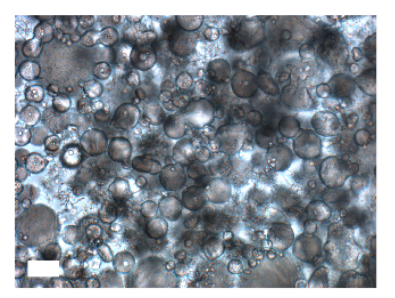

(c) $0.5^{\circ} \mathrm{C}$

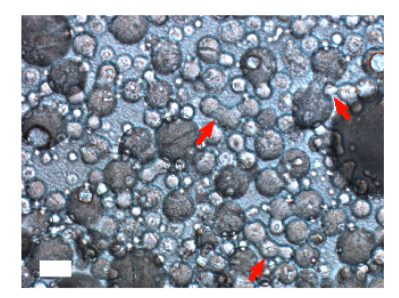

(d) $10^{\circ} \mathrm{C}$

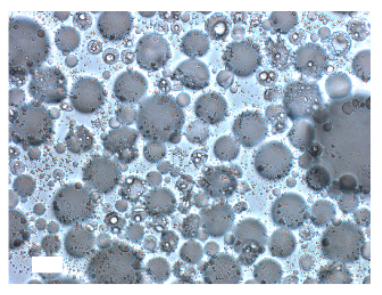

Figure S4. Optical images of the W/O emulsions stabilized by Span 80 in a mixture of $n$-decane and cyclopentane at (a) $21^{\circ} \mathrm{C}$, (b) $-15^{\circ} \mathrm{C}$, (c) $0.5^{\circ} \mathrm{C}$, and (d) $10^{\circ} \mathrm{C}$. Scale bar: $50 \mu \mathrm{m}$. 